\title{
Using culturally relevant case studies to enhance students' learning: a reflective analysis of the benefits and challenges for social work students and academics
}

\author{
Prospera Tedam, University of Northampton
}

\begin{abstract}
'Internationalising the curriculum', 'multi-cultural education', 'culturally sensitive' education, and 'culturally competent teaching' are terms often used to describe teaching and learning which provides opportunities for learning about multiple and diverse contexts in which specific aspects of knowledge can be applied. In social work education, there is a growing call for an international outlook in teaching and practice learning to enhance the experiences of learners and also to prepare graduates for working in a global context. Using a case study approach, this article will explore the particular experiences of a student of Zimbabwean origin and the adoption of an African focussed example used to facilitate the particular student's learning. In particular, Bandura's Social Learning Theory (1977) will be discussed drawing upon themes and ideas from Africa with the aim of demystifying and making accessible social work theory to a diverse student group. The paper concludes that the use of culturally relevant case studies is an effective and beneficial strategy to engage a diverse student group and calls academics to make creative and innovative use of their skills, knowledge and expertise in the area of social work pedagogy.
\end{abstract}

Keywords: African students; international social work; cross-cultural education; social work education; social work theory.

\section{Introduction}

The growing diversity within British society has resulted in similar levels of diversity within higher education institutions across England, Wales, Scotland and to a lesser extent, Northern Ireland. The reasons for this are varied, however it has been suggested that globalisation, migration and the Widening Participation (WP) agenda have contributed to the growing cultural and ethnic diversity in many universities across the UK. The United Nations estimates that around 190 million people worldwide currently live outside their country of birth (Lowell, 2007, p.7) The WP initiatives sought to widen access to higher education to groups such as women and Black Minority Ethnic (BME) people who historically had been underrepresented in many British Universities (QAA, 2008). However it is important to note that there is still an underrepresentation of some groups in 'elite' universities, and institutions providing higher education (Elevation Network, 2012).

As many British universities continue to see rising levels of diversity within their student cohorts studying on a range of academic and professional programmes, enrolments onto social work programmes are becoming more culturally and ethnically diverse. In 2008 and 2009, the General Social Care Council (GSCC) published statistics about enrolment onto social work programmes in the UK and this confirmed that after white British students, black African students were the second largest ethnic group accessing social work programmes. In particular, the increase in the numbers of African students on social work programmes across the United Kingdom has been recognised (Bartoli et al., 2008; Hussein et al., 2009 and Bernard et al., 2011) and there are ongoing debates about how the learning needs of this particular group of students is being met by 
social work educators, practice educators and other people involved in their learning experience. These levels of diversity, according to DeVita and Case (2003), presents challenges which existing models of teaching and learning will struggle to address.

This paper will present a reflective account of one such strategy used with the purpose of enhancing students learning experience and understanding of academic theoretical concepts. It will also highlight the challenges and benefits of such an approach for the student and for the educator.

It is important to begin with brief profiles of the student and lecturer in order to understand the context within which the learning and teaching activity took place. The Student is a Black female from the Southern African region who moved to England four years prior to enrolling on the undergraduate social work programme at a British University. Miller and Donner (2008) advise that when writing about issues of culture, race and/or ethnicity, it is essential to identify and locate one's own identity. For this reason, I wish to self-identify as a black African female social work practitioner and educator. Whilst there are similarities between the student and I, Gunaratnam (2003, p.102) cautions succinctly: 'although commonality can be seen as a form of empathic identification, it is vital that such empathy is interrogated and grounded in the recognition of the researcher as a separate and interactionally powerful producer, listener and interpreter'. This is what I seek to demonstrate within this paper.

\section{Culturally Relevant Teaching}

'We can't teach what we don't know' is the title given to his book and is the phrase used by Howard to describe the situation in which the 'teacher' and the 'learner' come from different cultural and racial backgrounds with little understanding and knowledge of literature and cross cultural teaching and learning techniques and strategies (Howard, 2006). The message here is that academics impart knowledge and stimulate ideas within the boundaries of their own knowledge and therefore by implication, it is impossible to teach from no knowledge. The ability to teach in a way that not only respects diversity but also includes culturally relevant content is central to the student experience.

Culturally responsive teaching, according to Gay (2000), is based on the assumption that for teaching to be effective, academic knowledge and skills need to be situated within the frames of reference and lived experiences of the learner. Social work education aims to prepare students for careers in the 'helping profession' where they will work with service users from a range of cultural and ethnic backgrounds, life experiences and circumstances. The delivery of the curriculum across the country contains disparate levels of culturally relevant content and it can be argued that the current social work curriculum in England provides minimal opportunities for this to be achieved. It could be suggested that its wide scope in the areas of social justice, equality and diversity, anti-discriminatory practice can be creatively and purposefully tailored to meet the needs of a range of students. Gordon (2007), speaking about the responsibility of academics, suggests that academics need to educate themselves about the world around them in order to enhance not only the content of their teaching but also their teaching and assessment styles. Previous studies have identified the importance of lecturers drawing upon a range of examples, case studies, literature and ideas that promote, respect and recognise diversity and that incorporate international and global perspectives wherever possible (Modood \& Acland 1998; DeVita \& Case, 2003; Gordon, 2007; Watson \& West, 2003). Colleagues and I have argued elsewhere (Bartoli et al., 2008) that programme teams must ensure that they explicitly encourage the use of non- 
European literature as the study found that black African students believed that drawing upon African authors in their academic work would disadvantage them in terms of their grades.

\section{The Social Work Context}

According to Walker et al. (2008), learning occurs at different levels and in many different ways. Learning on professional programmes such as social work involves a combination of classroom teaching and practice learning. Both components must be completed and passed in order for a student to complete their studies. A core area of the taught component of the programme is social work theory which is taught within a module and is often perceived by students as a difficult and complex area of social work education. Theory, in the view of many social work students, is far removed from practice however students have historically been required to become competent in their application of theory to practice. According to The Department of Health (2002), social work training and education needs to 'ensure that the teaching of theoretical knowledge, skills and values is based on their application to practice.' (p.3). More recently, the Social Work Reform Board (SWRB) has clearly stated that students of social work will need to 'know and use theories' in addition to methods and models of social work practice (College of Social Work, 2010; SWRB 2010). The Professional Capabilities Framework currently being implemented emphasises the importance of theoretical knowledge for social workers and provides a framework within which all practitioners will be supervised, appraised and progressed. Social work practitioners intervene in the lives of vulnerable people and it is important that their intervention is not based on assumptions, generalisations or on instinct. Practitioners have to be clear about the course of action they wish to pursue on behalf of a service user and the reasons behind this (Payne, 2005).

Oko (2008) posits that social work theory represents a range of assumptions, ideas and views which assist practitioners in making sense of the social world involving vulnerable service users. Theories used in social work have been drawn from disciplines such as psychology, sociology and biology and are used in practice to provide evidence for intervention and opportunities for understanding the wider and often more complex world of the service user/s and their families. There are however varying ideas about how these theories are taught within the classroom setting and subsequently, how this knowledge is transferred to the practice arena (Lesser \& Cooper, 2006). Student social workers are expected to be able to name and articulate theoretical perspectives that may assist them in extending their knowledge about a particular service user's situation and ultimately the most effective strategy for intervention. Theories are used to explain what is happening within a given context often as a result of analysis and observation.

For the purposes of this paper, the discussion to follow refers to the work undertaken with one student, with the view to extending and developing her understanding of Bandura's Social Learning Theory (1977) using what I perceived to be a familiar, culturally relevant example. This was done in my role as the personal academic tutor (PAT) for this student, and not the module leader. The timing of this work was incidental rather than planned as there had been concerns expressed by practice assessors about the gaps in this student's knowledge. These concerns about BME students' progression and attainment on social work programmes is not new (GSCC, 2009; Hussein et al., 2009; Bernard et al., 2011). It is important to add that the student did not explicitly request additional support from me or any other tutor for that matter, a situation which Maundeni (1999) describes as reluctance on the part of African female university students to ask for support to enhance their understanding of the taught curriculum. Having an awareness of this reluctance helped me make the decision to offer this additional support. In the late 1980's, Stein posited that 'we neglect our responsibility in social work education when we do not provide a world view to 
our students and we neglect our responsibility to our profession and our government when we do not contribute to international service' (cited in Healy, 2001, p.135). Watson and West (2003) add to this debate by suggesting that black students of social work require additional support as they are a part of an institution which does not reflect their diverse world views.

I began by considering Fook's view that 'ways of teaching and learning need to be scrutinised for their capacity to foster ability to learn from practice experience, to formulate contextual knowledge, to be open to differences and to reaffirm the broader values and missions of the social work profession' (Fook, 2007, p.38). Osmond and O'Connor (2004) identify a number of ways in which social work practitioners share and express their knowledge and understanding in the practice context. Case examples, metaphors and stories are vehicles through which practitioners understand and make sense of some knowledge.

This paper will examine the value of drawing from familiar case studies as a means to explore and explain a number of social work theories.

\section{Social Learning Theory with an African Flavour}

The phrase 'African flavour' is used here to denote the use of specific ideas, themes and concepts drawn from cultural artefacts, processes and systems within the African continent and used with the aim of enhancing the learning process for African students studying in higher education institutions outside their home countries. As a social work educator, my world view is shaped by my culture and experiences which in turn shapes my teaching. It is therefore not unreasonable to expect that students who are familiar with some of these processes, artefacts and systems will use them to enhance their learning. The main ideas proposed are not dissimilar from what Asante (1980) refers to as Afrocentricity, which is about seeing the world from an African perspective and validating the experiences of African people in terms of slavery, oppression, racism and segregation. He goes on to say that the main problems faced by people of African descent are the conscious and unconscious adoption of the worldview of the west. Rooted in African philosophy, the Afrocentric paradigm determines that behaviour, attitudes and ideas are dynamic and viable and as such presents African students with an opportunity to draw from these ideas as a means for making sense of western academic literature and philosophy. The discussion which follows takes Bandura's Social Learning Theory (1977) and embeds it within a framework which is culturally relevant to the particular student.

Social Learning Theory works from the premise that people learn from one another and that there are certain conditions which make this 'learning from others' possible. These conditions, according to Bandura (1977) are 'attention', 'retention', 'reproduction' and 'motivation'. In order to explore this with the student, I provided the example below, beginning with the context of collecting water, an activity which is frequently undertaken in Africa.

A female aged between 6 and 10 in many African societies is required to learn the art of collecting water from the stream, river or pond, usually a few kilometres from home. This collection of water is often a gendered role and so young girls start off by accompanying their mother or another female to the stream and simply walking alongside them and watching how this water is collected, raised to the head and then balanced for the duration of the journey back home. This is the process which could be likened to what Bandura refers to as paying close 'attention'. 
Following on from this stage, the young girl is required to retain and remember the strategies used to collect water, the shortest and safest route home and how and where to deposit the water collected. Usually, water is collected into a basin or bucket. This stage parallels Bandura's next stage which is 'retention'.

The 'reproduction' stage is the third stage and involves the young girl attempting this process on her own, with initial supervision by an older female member of the family. The young girl works out what size to begin with and gradually works her way to using a large size basin or bucket which can take 60-100 litres of water.

The fourth final condition is one of 'motivation'. The young girl must be motivated to learn the art of collecting water. The wider family expect this of her and the reward tends to be verbal praise and encouragement, not only by the immediate family, but also by peers in school and surrounding villages. This is also captured in Table 1 below for ease of reference and understanding

\begin{tabular}{|c|l|}
\hline Social Learning Theory (Bandura) & \multicolumn{1}{|c|}{ Links to Collecting Water } \\
\hline Attention & $\begin{array}{l}\text { This collection of water is often a gendered role and so } \\
\text { young girls begin by accompanying their mothers to the } \\
\text { stream and simply walking alongside them and watching } \\
\text { how this water is collected, raised to the head and then } \\
\text { balanced for the during of the journey back home. }\end{array}$ \\
\hline Retention & $\begin{array}{l}\text { The young girl needed to retain and remember the } \\
\text { strategies used to collect water, the shortest and safest } \\
\text { route home and how and where to deposit the water } \\
\text { collected. Usually, water is collected into a basin or } \\
\text { bucket. }\end{array}$ \\
\hline Reproduction & $\begin{array}{l}\text { This stage involves the young girl attempting this process } \\
\text { on her own, with initial supervision by an older female } \\
\text { member of the family. The young girl works out what size } \\
\text { to begin with and gradually works her way to using a } \\
\text { large size basin or bucket which can take } 60-100 \text { litres of } \\
\text { water. The goal at this stage is not to spill the water. }\end{array}$ \\
\hline Motivation & $\begin{array}{l}\text { The young girl must be motivated to learn the art of } \\
\text { collecting water. The wider family expect this of her and } \\
\text { the reward can be verbal praise and encouragement, not } \\
\text { only by the immediate family, but also by peers in school } \\
\text { and surrounding villages. }\end{array}$ \\
\hline
\end{tabular}

Table 1: Social Learning Theory with an African flavour. Developed from Bandura (1977)

\section{Challenges \& Benefits}

In this section, I describe and reflect upon the work undertaken with this student and attempt to highlight the challenges and benefits associated with this type of student-centred work. 


\section{Time}

One of the main challenges was finding the time to support this student to the extent required and expected. I had to make difficult decisions about how much time I could spare and how to be equitable with my allocation of time to different students within my tutor group. The issue of time (or lack of it) is central to any student-tutor relationship. I estimate that this intervention with the student took up to 5 hours to complete the outcome of which seemed to be positive. As a personal academic tutor to many students, time was of the essence both in terms of my time and also the requirements for this student to be conversant with a range of social work theories by the end of a specified practice learning period. Closely linked to the issue of time is the possibility of creating a culture of dependency.

\section{Dependency}

Ensuring that additional work with this student did not leave her vulnerable and dependent on my ongoing support, additional tuition was something which I had to be mindful of as this had the potential to disadvantage not only her but also other students. There needed to be a clear message that this strategy had been used as a means to boosting her self-confidence and reaffirming her ability to study at degree level; and in some ways could be used as an ongoing strategy to benefit the whole cohort or groups of students, not only individual students.

\section{Knowledge}

I often reflect on the possible outcome for this student if I did not possess the knowledge to support her in this way. I feel that being in the 'right place at the right time' meant that I was involved in this student's learning from the beginning and was aware of her strengths and areas for development.

\section{Context}

Whilst every educator's first loyalties should be to their students or learners, I was acutely aware that the context of my involvement was at the crucial point where concerns about the student's academic progress came into question. There was, therefore a degree of urgency for support and innovation to ensure that 'we' (as educators) had done all we could to enhance the students chances of progression as well as her overall learning experience.

\section{National and regional differences}

Recognising, acknowledging and respecting national and regional differences was a key challenge while undertaking this work because of the implicit assumptions behind the case study used. While I was aware that the student had not long been in the UK, I was unsure about the context of her life prior to enrolling on the course and therefore there was a risk of her not understanding the context of a young girl learning to carry water, or indeed differences in expectations of young girls within her own cultural context. De Anda (2008) cautions educators who are working with students from a range of cultures to be aware of not only their own cultural lenses, but also to recognise students' cultural lenses which may be similar or different to our own and with the potential to provide additional ways of viewing the world.

\section{Patronising and the Risk of becoming simplistic}

Whilst it was not my intention to appear to patronise or exacerbate this student's anxiety about her learning, nor indeed about the difficulties she was experiencing, by using non-academic language 
and potentially providing what could be perceived as an 'easy' explanation of what can be a difficult subject, I was at risk of the student feeling patronised, belittled or even disrespected. In formulating the case example I used, I needed to be cautious of not undermining the depth and complexity of Bandura's Social Learning Theory. The risk of oversimplifying concepts and ideas could be misleading for the student and further create barriers to her learning on other equally complex ideas and theoretical perspectives. I took the view that once the student had understood the stages through which one person learns from another, she would be able to draw upon similar frameworks to enhance her understanding of other areas of social work theory and practice.

In spite of the challenges and dilemmas considered above, there were a number of benefits for the student, and the other stakeholders in this learning and teaching relationship, which need to be highlighted and celebrated.

\section{Benefits}

\section{Validated the use of non-western ideas and concepts}

For some of our students from non-western countries, the use of non-western literature and epistemology is rarely on their agenda. The reasons for this are varied and often include a recommended reading list which reflects the dominant western discourse and scholarship. The study by Bartoli et al. (2008) highlighted black students anxieties about using 'foreign' literature in their coursework for fear that such an approach would result in them failing or achieving low grades for assessed work. For this student then, the lecturer's use of familiar, African concepts and ideas served to promote and validate the importance of drawing more widely for the purposes of learning and future scholarship.

\section{Student}

For this student, the use of this case study enhanced her understanding and knowledge base as well as provided her with the opportunity to connect with familiar concepts and ideas. As LadsonBilling (1994) suggests, this form of teaching empowers students emotionally, intellectually, socially and politically. This student's growth, development and academic progress and successful graduation are testimony to the positive impact of this teaching strategy. The student subsequently expressed their gratitude in an e-mail.

\section{Tutor and University}

Given that I had multiple roles in relation to this student (personal academic tutor, programme leader and placement visiting tutor) it meant that I was also aware of the various strands of learning the student had been engaged in and was able to assist her in making necessary links to the wider social work context and her placement setting in particular. The positive outcome enhanced the student's experience in the area of tutorial support and inclusion as well as providing opportunities for creativity and innovation on the part of the tutor. Watson and West (2003) acknowledge the difference in knowledge and power between the tutor and the tutee and emphasise the need for the tutor to acknowledge the students strengths, existing knowledge and skills as this strategy provides a foundation for an empowering relationship which in turn fosters the students learning.

\section{Placement Agency}


At the time this work was undertaken, the student was part-way through her learning in the practice setting. The onsite placement supervisor and the practice assessor acknowledged and commended the development in the student's confidence and competence following the additional sessions provided. It would be unfair and unethical to attempt to take credit for the student's overall success, however by her own admission, this level and type of support had a direct positive impact on her learning and ultimately the outcome.

\section{Final Reflections and Conclusion}

This paper has highlighted the importance of using culturally appropriate case studies when working with social work students from different backgrounds and cultures. Whilst it would be impossible to match social work educators with students from similar cultures and backgrounds, there is indeed value in being aware of the range of skills and expertise among social work educators and drawing on this experience and knowledge at various points during the course of our students' studies.

The value of drawing from non-western or non-dominant ideas and examples in social work education in the UK is both timely and relevant. Globalisation and the changing nature of professional social work means that social work education needs to be responsive to the needs of the international community, irrespective of the local and national context in which the teaching and learning occurs. This can be done through what Healy (2001) describes as the infusion model, where international perspectives are integrated into the existing curriculum at all levels of social work education. It is near impossible to be able to meet the unique learning needs of individual students within a classroom or large group environment, however Blunt (2008) suggests that this can be partly achieved by providing opportunities and activities to supplement general lectures thus being creative and innovative.

This and other similar case examples can be used with all students to enrich their cross-cultural learning and to provide fertile ground for future integration of non-western ideas and concepts with particular cohorts of students. Upon reflection, I used this approach in the early days of my career and at the time, would have felt uncomfortable widening out to other students. This feeling mirrors what Bell Hooks (2010) describes as my limiting black female intellect to within the black community for fear of rejection and resistance. Over the years, my own self confidence as a teacher and early career researcher has placed me in a position where I would feel less hesitant to explore the issues contained within this paper with a wider and more varied audience. My own journey through higher education as a black female has left me with an interest in developing innovative teaching and learning tools to meet the needs of the growing diversity of students whose future employment will be in a culturally diverse world.

Howard (2006) suggested that 'you can't teach what you don't know' and the truth of this statement cannot be overstated; however as a colleague social work educator observed: 'we can begin with what we know'.

\section{References}

Asante, M. (1980) Afrocentricity: The Theory of Social Change. Buffalo, NY: Amulefi Publishing Company. 
Bartoli, A., Kennedy, S. and Tedam, P. (2008) 'Who is failing to adjust? Black African student experience of practice learning in a social work setting'. Journal of Practice Teaching \& Learning. 8 (2): 75-90.

Bandura, A. (1977). Social Learning Theory. New York: General Learning Press.

Bell Hooks (2010) Teaching Critical Thinking: Practical Wisdom. New York: Routledge.

Bernard, C., Fairtlough, A., Fletcher, J. and Ahmet, A. (2011) Diversity and Progression among Social Work Students in England. Goldsmiths University of London.

Blunt, K. (2008) 'Social Work Education: achieving transformative learning through a cultural competence model for transformative education'. Journal of Teaching in Social Work. 27 (3-4): 93-114.

College of Social Work (2010) Professional Capability Framework. Available online www.collegeofsocialwork.org (accessed $18^{\text {th }}$ June 2012).

De Anda, D. ( 2008) Teaching social work with multi-cultural populations: a holistic approach to learning. Journal of Teaching in Social Work. 28, (3-4): 431-449.

Department of Health (2002) Requirements for Social Work Training. London: Crown Copyright.

DeVita, G. and Case, P. (2003) 'Rethinking the Internationalisation Agenda in UK Higher Education'. Journal of Further and Higher Education. 27 (4): 383-398.

Elevation Network (2012) Race to the top: The Experiences of Black Students in Higher Education. London. The Bow Group

Fook, J. (2007) Uncertainty: the defining characteristics of social work? In Lymberry, M. And Postle, K. (eds) Social Work: A Companion to Learning. London: Sage.

Gay, G. (2000) Culturally Responsive Teaching: Theory, Research and Practice. New York: Teachers College Press.

General Social Care Council (2009) Raising Standards: Social Work Education in England 20078. London: GSCC.

Gordon, J. (2007) 'What can White faculty do?'. Teaching in Higher Education. 12 (3): 337-347.

Gunaratnam, Y. (2003) Researching 'Race' and Ethnicity: Methods, Knowledge and Power. London: Sage

Healy, L. M. (2001) International Social Work: Professional Action in an Interdependent world. New York: Oxford University Press.

Howard, G. R. (2006) We Can't Teach What We Don't Know: White Teachers, Multiracial schools. Second Edition. New York: Teachers College Press. 
Hussein, S., Moriarty, J. and Manthorpe, J. (2009) Variations in Progression of Social Work Students in England: Using Student Data to Help Promote Achievement. London: Social Care Workforce Research Unit, King's College London and General Social Care Council.

Ladson-Billings, G. (1994) The Dream keepers: Successful Teachers of African American Students. San Francisco: Jossey-Bass.

Lesser, J. G. and Cooper, M. (2006) 'Theory and practice: An integrative model linking class and field. Journal of Teaching in Social Work. 23 (3-4): 121-135.

Lowell, L. (2007) Trends in International Migration Flows and Stocks, 1975-2005. OECD Social, Employment and Migration Working Papers No 58: Employment, Labour and Social Affairs Committee, Paris.

Maundeni, T. (1999) 'African females and adjustment to studying abroad'. Gender and Education. 11 (1): $27-42$.

Miller, J. and Donner, S. (2008) 'More than just talk. The use of racial dialogues to combat racism’. Social Work with Groups. 23 (1): 31-53.

Modood, T. and Acland, A. (1998). Race and Higher Education: Experiences, Challenges and Policy Implications. London: Policy Studies Institute.

Oko, J. (2008) Understanding and Using Theory in Social Work. Exeter. Learning Matters.

Osmond, J. and O'Connor, I. (2004): 'Formalizing the unformalized: practitioners' communication of knowledge in practice’. British Journal of Social Work. 34 (5): 677-692.

Payne, M. (2005) Modern Social Work Theory. Third Edition. Hampshire: Palgrave Macmillan.

Quality Assurance Agency (2008) Outcomes from institutional audit: Institutions' arrangements to support widening participation and access to higher education: Second series. Available online:

http://www.qaa.ac.uk/Publications/InformationAndGuidance/Pages/Outcomes-from-institutionalaudit-Second-series-Institutions-arrangements-support-widening-participation-access-HE.aspx (accessed $2^{\text {nd }}$ November 2012).

Social Work Reform Board (2010) Building a safe and confident future: one year on. Detailed proposals from the Social Work Reform Board. London. Crown Copyright.

Walker, J., Crawford, K. and Parker, J. (2008) Practice Education in Social Work: A handbook for Practice Teachers, Assessors and Educators. Exeter: Learning Matters.

Watson, D. and West, J. (2003) The role of the tutor in social work education: Building an emancipatory tutorial relationship. Social Work Education: The International Journal. 22 (2): 139-149.

\section{About the author}

Prospera Tedam is a Senior Lecturer in Social Work at The University of Northampton. 
Email: prospera.tedam@northampton.ac.uk 